\title{
Cultos a filósofos griegos antiguos en Diógenes Laercio: evidencias y funciones
}

Cults to Ancient Greek Philosophers in Diogenes Laertius: Evidences and Functions

\section{Sergi Grau}

\section{CpenEdition}

\section{Journals}

\section{Edición electrónica}

URL: https://journals.openedition.org/mythos/2906

DOI: $10.4000 /$ mythos. 2906

ISSN: 2037-7746

\section{Editor}

Salvatore Sciascia Editore

\section{Referencia electrónica}

Sergi Grau, «Cultos a filósofos griegos antiguos en Diógenes Laercio: evidencias y funciones », Mythos [En ligne], 14 | 2020, mis en ligne le 31 décembre 2020, consulté le 05 octobre 2021. URL : http:// journals.openedition.org/mythos/2906; DOI : https://doi.org/10.4000/mythos.2906

Este documento fue generado automáticamente el 5 octubre 2021.

Mythos 


\title{
Cultos a filósofos griegos antiguos en Diógenes Laercio: evidencias y funciones
}

\author{
Cults to Ancient Greek Philosophers in Diogenes Laertius: Evidences and
}

Functions

Sergi Grau

Este trabajo es parte del proyecto de investigación «La construcción del pasado en la Grecia arcaica y clásica: mecanismos compositivos, genealogías y catálogos", dirigido por J. Carruesco y X. Riu, y financiado por el Ministerio de Ciencia, Innovación y Universidades (PID2019-110908GBI00), y también del grupo de investigación "Logotekhnia. Estudis de cultura grega antiga», dirigido por X. Riu (2017 SGR 894).

1 En las biografías de los filósofos de Diógenes Laercio, al menos en algunas de las versiones que él reporta, el filósofo aparece a menudo como un personaje vilipendiado, incluso odiado en vida por sus conciudadanos. Se confirma, pues, lo que señalaba

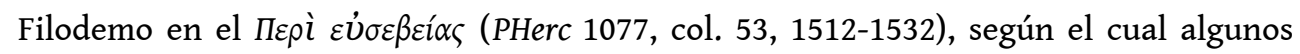
filósofos fueron acusados por su forma de vida y por su doctrina, otros tuvieron que exiliarse de sus ciudades, algunos incluso acabaron sentenciados a muerte, y todos fueron ridiculizados en las comedias': esta es, ciertamente, la imagen del filósofo en la mayoría de las diversas tradiciones biográficas que nos han llegado². Sin embargo, una vez que muere, generalmente le son tributados grandes honores. Los términos precisos,

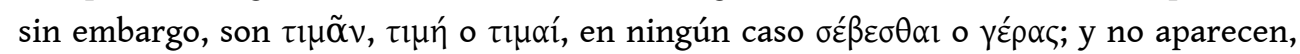
tampoco, prácticamente en ningún caso, las expresiones que son habituales en los

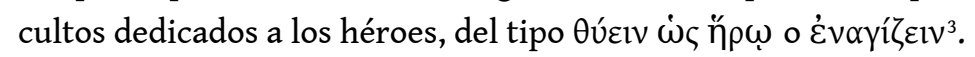

2 Este proceso responde a una actitud ambigua típica de los griegos de la Antigüedad hacia sus grandes personajes: la hostilidad biográfica hacia quienes son excepcionales se convierte en una expresión reverencial hacia el gran hombre una vez muerto ${ }^{4}$, siguiendo la misma mentalidad, propia de la religiosidad griega antigua, que instaura cultos en honor de los héroes cuya vida y cuya muerte han comportado sufrimientos 


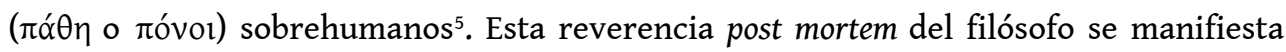
particularmente en los honores funerarios que recibe de parte de su ciudad inmediatamente después de su defunción, cualquiera que sea su forma de morir, incluso si la biografía lo había calificado negativamente: los honores funerarios, como en el caso de los héroes de la tradición religiosa, se otorgan a un filósofo independientemente de sus vicisitudes vitales o de lo gloriosa o no que sea su forma de morir ${ }^{6}$.

\section{Honores fúnebres otorgados a los filósofos por sus ciudades}

3 De manera similar, asimismo, al tipo de honores funerarios otorgados a los poetas en la tradición biográfica ${ }^{7}$, los filósofos reciben los honores que la actividad filosófica debería implicar idealmente. Uno de los puntos de contacto más interesantes entre los honores conferidos a los filósofos y el tipo de honores funerarios recibidos por los poetas se encuentra en la biografía de Platón: vinculado a Apolo por la fecha misma de su nacimiento, con una versión de partenogénesis apolínea ya en las fuentes antiguas (DL III 2) ${ }^{8}$, Eliano (VH XII 45; X 21) lo identifica explícitamente con Píndaro porque, como a él, de pequeño las abejas le depositaron miel en los labios ${ }^{9}$, como lo hicieron asimismo con Sófocles, según el testimonio de Aristófanes (fr. 679 K-A = TGF T 1.22) y de Filóstrato (XIII 3). Y Apolo mismo fue quien sancionó la apoteosis de Platón en el momento de su muerte (DL III 45). Es muy significativo que el filósofo que pretendió reemplazar las formas tradicionales de comunicación en Grecia por la suya propria ${ }^{10}$ haya quedado tan claramente conectado en la tradición biográfica con los poetas a quienes intentaba suplantar, y precisamente con Píndaro y Sófocles, que son los que recibieron una muerte más dulce, en la mayoría de las versiones, juanto a los Siete Sabios y Homero, con quien comparte además la genealogía divina, e incluso concretamente apolínea; y debemos agregar que Platón es el único filósofo antiguo, precisamente, a quien se le atribuye una genealogía divina.

De hecho, las formas de veneración de los filósofos en el momento del sepelio son bastante claras en las biografías laercianas: subrayan que toda la ciudad sigue la procesión fúnebre del filósofo que acaba de morir, como una exhibición de gran estima pública por el personaje; los epitafios, también públicos, señalan el carácter ilustre del filósofo y el orgullo de la ciudad por considerarlo hijo suyo; y, en algunos casos particularmente gloriosos, se añade además la erección de estatuas y efigies de bronce, depositadas en espacios sagrados, que a menudo van acompañadas de la institución de un culto heroico alrededor de la tumba del filósofo, transformado en un altar. La presencia de estatuas entre los honores funerarios de algunos filósofos, además, es particularmente interesante por el hecho de que «the erection of a complimentary statue may have often served as the indirect incentive to a later cult $»^{11}$. Sabemos, gracias a Laercio, de las estatuas de Platón (DL III 25), de Sócrates, en bronce (DL II 43), y que las de Aristóteles y varios miembros del Perípato se erigieron en el contexto de un Museo, según las prescripciones testamentarias de Teofrasto (DL V 51-52). 


\section{Evidencias de cultos heroicos dedicados a filósofos en Diógenes Laercio}

5 Sin embargo, en las biografías de los filósofos de Diógenes Laercio, no suele aparecer en el cuerpo del relato ninguna referencia más o menos desarrollada a estos cultos, sino que el epigrama que se les dedica al final, generalmente compuesto por él mismo, pero también por otros, es la forma habitual de sancionar la apoteosis de un filósofo. Rara vez aparece alguna referencia a este proceso en el cuerpo de la narración biográfica propiamente dicha, si no es, significativamente, para denunciar su falsedad.

Por lo que se deduce de las vidas laercianas, son pocos los filósofos que se consideran divinos ya por sus actos en vida: Epiménides, a quien los antiguos consideraban el

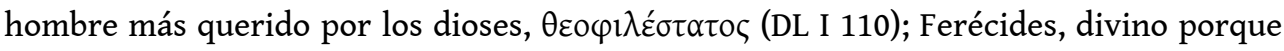
profetizaba (DL I 116) y conocía el lenguaje de los dioses (DL I 119); Pitágoras, por supuesto, siempre rodeado de un halo divino (por ejemplo, DL VIII 14); Empédocles, que se llamó a sí mismo dios inmortal (DL VIII 62 = DK 31 B 112), y así lo califica toda la tradición biográfica; Demócrito, que adquirió gracias a sus predicciones la reputación de ع̌v $\theta \varepsilon \circ \zeta$ (DL IX 39); y Menedemo, quien se presentó como un personaje inspirado por los dioses cuando caminó disfrazado de Furia y afirmó haber llegado del Hades para observar las maldades de los hombres e informar inmediatamente a los dioses infernales (DL VI 102), aunque este caso se trata más bien una parodia típicamente cínica $^{12}$.

7 Aún menos son los filósofos de quienes se dice explícitamente que fueron venerados mediante un culto por sus conciudadanos: a Epiménides los cretenses le ofrecían

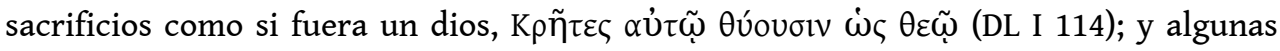
versiones afirman lo mismo de Empédocles, después de su misteriosa desaparición: Pausanias, su discípulo, afirmó que era coveniente sacrificar en su honor como a quien

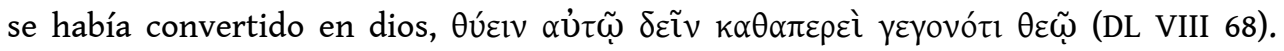
Estos son los dos únicos casos en las vidas laercianas en que encontramos los términos técnicos $\theta$ úcıv $\dot{\omega} \varsigma$ $\theta \varepsilon \tilde{\omega}$ para calificar un culto heroico. Hay que añadir, además, a Anaxágoras, que recibía un culto anual en Lámpsaco (DL II 14-15), y, según Eliano (VH VIII 19), se erigió un altar allí en su honor donde se grabó Noṽ y y A $\lambda \hat{n} \theta \varepsilon i \alpha^{13}$. El hecho de que las cenizas de Solón fueran dispersadas por la isla de Salamina (DL I 62) debe entenderse, según Farnell, como «the desire to settle his guardian-spirit in the island and suggests hero-cult; for the same history is told of Phalantos at Tarentum, who was heroized in the latter city» ${ }^{14}$. El epigrama laerciano insiste en sus extraordinarias habilidades como legislador, lo que le hizo digno de ser heroizado (DL I 63):

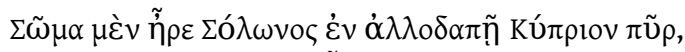

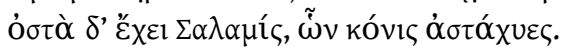

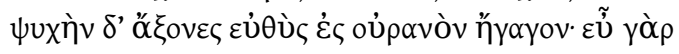

$\theta \tilde{\eta} \kappa \varepsilon$ vó

El cuerpo arrasó de Solón de la Chipre lejana el fuego,

la isla sus huesos guardó, polvo que espigas criaba.

Mas su alma las ruedas derecho al cielo llevaron, de buenas

leyes cargadas y tan leves que apenas pesaban. [Trad. L.-A. Bredlow]

Era, por supuesto, una costumbre griega considerar a los grandes legisladores de sus ciudades ${ }^{15}$ sus segundos fundadores (vÉol $\left.\kappa \tau i ́ \sigma \tau \alpha l\right)$, y es por ese motivo que «doubtless many of them were heroized $»^{16}$, como Licurgo, que recibió culto heroico en su ciudad ${ }^{17}$. 
Del mismo modo, siempre según Diógenes Laercio, para algunos de los denominados

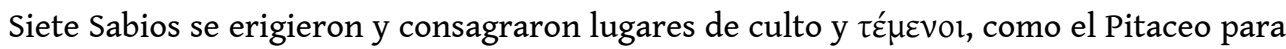
Pítaco, en Mitilene (DL I 75), o el Teutameo (del nombre de su padre, Téutamo) para Biante, en Priene (DL I 88) ${ }^{18}$, ciertamente para recompensar sus servicios a la patria, como sucedió con aquellos que murieron por defenderla ${ }^{19}$. Pausanias (III 16, 4) informa también de la existencia de un ทं $\rho \tilde{\omega} o v$ consagrado a Quilón, heroizado debido a su

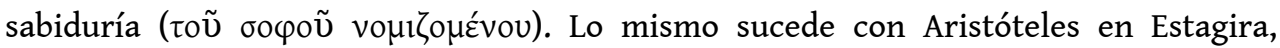
donde fue legislador y benefactor (DL V 2; Vita Marciana 17 Düring). Sin embargo, no parece que en el Liceo haya habido un verdadero culto al fundador, como se desprende de las instrucciones que Teofrasto dio en su testamento a propósito del lugar adecuado para el busto del maestro (DL V 51) 20: $^{20}$

De lo prestado a Hiparco, quiero que se haga lo siguiente: primero, que se acaben las obras del Museo y las estatuas de las diosas, y que a éstas se les añada todo lo que se pueda para hacerlas más hermosas; luego, que la efigie de Aristóteles se coloque en el santuario, así como las demás ofrendas que antes se hallaban en el santuario

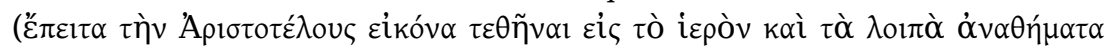

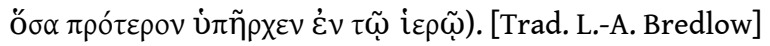

Una minúscula pero muy interesante evidencia de culto en las biografías de Diógenes Laercio es el que Parménides ofreció a su maestro Aminias, cuando construyó un

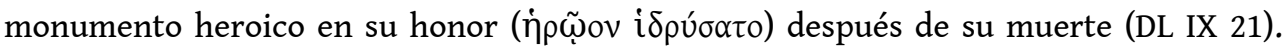
Asimismo, los decretos, estatuas y honores que para Zenón de Cicio estableció la ciudad de Atenas (DL VII 11-12 y 29) nos inducen a pensar en la institución de un culto. Así, al menos, lo da a entender un epigrama de Antípatro de Sidón (App. Anth. Pal. III 104) que reporta Laercio (DL VII 29):

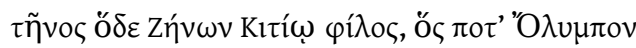

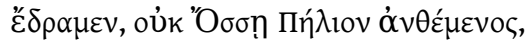

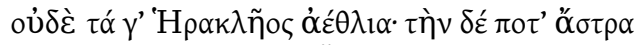

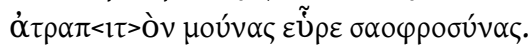

Yace aquí de Cicio la prenda, Zenón, que al Olimpo

ascendió sin volcar sobre la Osa el Pelión,

ni padecer los trabajos de Heracles: el rumbo a los astros

él por la fuerza lo halló sola de la sensatez. [Trad. L.-A. Bredlow]

\section{Platón}

En realidad, sin embargo, debemos afirmar que no encontramos apenas rastro en los relatos biográficos de Diógenes Laercio de las narraciones de heroización que se hacen evidentes y habituales en autores posteriores. Por ejemplo, en las vidas tardías, la heroización de Platón es narrada de forma canónica: una mujer, a quien Boyancé quiso identificar con una de sus discípulas, Axiotea de Fliunte (DL III 31), ${ }^{21}$ se dirigió después de la muerte del maestro al oráculo, ciertamente el de Delfos, para preguntar si debería colocarse una efigie de Platón junto a las imágenes de los dioses; el oráculo respondió (Vita Platonis Anonyma 218-224):

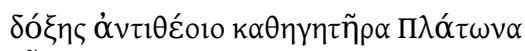

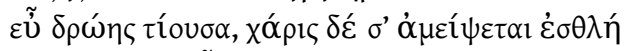

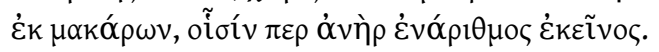

Al maestro Platón, de gloria igual a la de los dioses,

harás bien en venerarlo: una noble gracia te corresponderá

de parte de los bienaventurados, entre los cuales ya se cuenta este hombre. 
11 Como es bien sabido, Delfos a menudo sancionó heroizaciones históricas, y el proceso habitualmente descrito es idéntico a este de Platón: los ciudadanos recurren al oráculo de Delfos y su respuesta es que se debe honrar al personaje, a menudo un atleta, porque se ha convertido en un héroe que no debe ser ya contado entre los mortales ${ }^{22}$. Diógenes Laercio no es tan explícito, como señalábamos, en el cuerpo del relato biográfico, pero los epigramas consagrados a Platón son, en cambio, muy claros al declarar su apoteosis (DL III 43-44) $)^{23}$ :

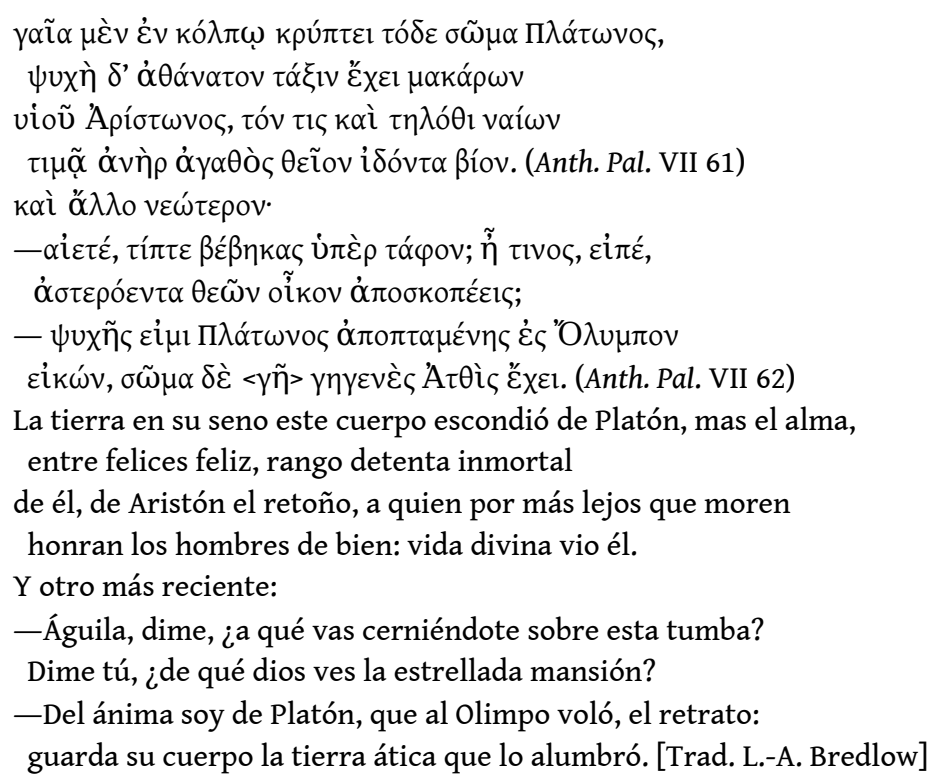

\section{Epicuro}

12 Caso aparte es el de Epicuro: como afirmaba Pierre Boyancé, «le penseur, qui fut l'adversaire les plus acharné et de la providence des dieux et de l'immortalité de l'âme, est peut-être celui dont les disciples vénérèrent le plus pieusement le souvenir» ${ }^{24}$. Sin embargo, la veneración proviene de las obras mismas del filósofo, según las cuales el hombre sabio es un dios (Men. 124, 134) ${ }^{25}$, que tiene la beatitud como característica más destacada (Men. 123): parece razonable, por consiguiente, que los discípulos identificaran la imagen del sabio con la del maestro, y procedieran de esta forma a su divinización. Todos los detalles de su culto quedaron prescritos en su testamento: los

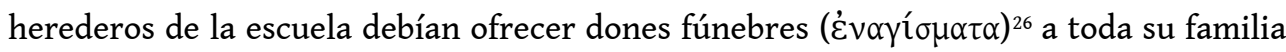
junto a él en su dies natalis, y también honrar la memoria de Metrodoro y la suya propia el día veinte de cada mes (DL X 16-18) ${ }^{27}$. Incluso Cicerón se sorprendía de estas prescripciones, no sin un punto de malicia (Fin. II 31, 101), y Plinio (N. H. XXXV 5) ${ }^{28}$ dejó descrito el ritual.

Extrañamente, Boyancé no veía signos de apoteosis, ni siquiera de heroización, en este culto $^{29}$, sino tan sólo un grupo que, como en la Academia o en el Perípato, llevaba una vida «organisé dans les cadres d'une religion»" ${ }^{30}$. Más recientemente, sin embargo, el culto a Epicuro ha sido estudiado sistemáticamente por diferentes autores ${ }^{31}$. Diskin Clay, por ejemplo, comprende «the provisions of Epicurus' will as evidence for a cult of heroes among the Epicureans $»^{32}$, como ya había observado Deneken ${ }^{33}$. Clay ve en el culto a las estatuas del maestro y en las celebraciones festivas de su dies natalis una prueba de que Epicuro «was the founder of the cults of his philosophical community and in a true sense a heros ktistes, and it is in his life that we see the most eloquent 
exemplification of the attempt to imitate the divine (ómoí $\omega \sigma 1 \zeta \theta \varepsilon \tilde{\omega}))^{34}$; de hecho, podríamos tener una confirmación arqueológica de un verdadero lugar de culto en un pasaje de Heliodoro $(I 16,5)$ donde se decribe un $\mu v \tilde{\eta} \mu \alpha$ de los epicúreos en las fronteras de Atenas ${ }^{35}$. Epicuro, en efecto, fue un deus mortalis, recibió la más alta veneración por parte de sus discípulos y fue objeto de una imitatio. Nada de este culto y veneración, sin embargo, puede deducirse de la narración biográfica que Diógenes Laercio dedica a Epicuro en su décimo libro: nada indica el $\sigma \varepsilon \beta \alpha \sigma \mu o ́ \varsigma$ de los discípulos hacia el maestro

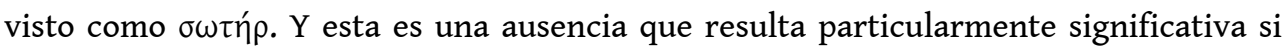
tenemos en cuenta todo el material, a menudo inédito, que Laercio aporta del filósofo y su devoción particular por el epicureísmo, que motivó incluso que Wilamowitz y Crönert lo consideraran un epicúreo ${ }^{36}$.

\section{Apoteosis celestes de los filósofos}

14 Aunque otros filósofos, como, particularmente, Diógenes cínico ${ }^{37}$, muestran en sus biografías signos bastante evidentes de heroización, ésta no es tampoco explícita en Laercio. Sólo los epigramas (DL VI 76-78), como hemos observado para Platón, consagran su entronización cultual, principalmente mediante la imagen de una apoteosis celeste, junto a los Olímpicos. Es particularmente interesante, en este sentido, el que Laercio dedica a Sócrates (DL II 46):

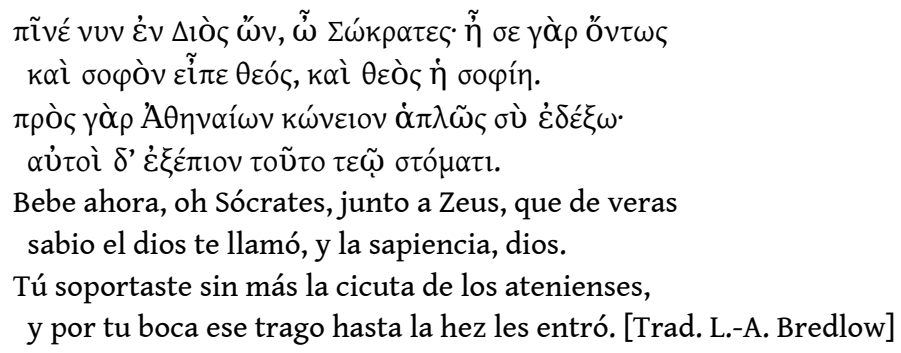

Sócrates aparece aquí explícitamente calificado a la manera de un héroe que ha experimentado una apoteosis celestial debido a su sabiduría; en cambio, no tenemos ninguna referencia a culto alguno en su honor, un caso extraño, habida cuenta de su tradición biográfica y, sobre todo, de las características marcadamente heroicas de su muerte ${ }^{38}$. No faltan para él, como para Platón o Pitágoras, observaciones de su carácter divino o casi divino: él mismo se compara, por ejemplo, con Aquiles (Platón, Crit. 44b) y con Heracles (Platón, Ap. 22a), y recalca que su deber es de orden divino, proclamado por boca de Apolo mismo (Platón, Ap. 20e, 21a, 27b, 30c) ${ }^{39}$.

Este proceso de apoteosis celestial a través del epigrama es particularmente frecuente cuando la muerte del filósofo ha sido violenta, lo cual equivale a decir, en la tradición biográfica, glorificante: las biografías destacan que sus enemigos han podido destruir su cuerpo, pero no a él mismo. Este es el caso de Anaxarco, torturado hasta la muerte por el tirano Nicocreonte de Chipre, para el cual Laercio compone un epigrama triunfal, siguiendo las palabras mismas del filósofo que aparecen en el cuerpo del relato

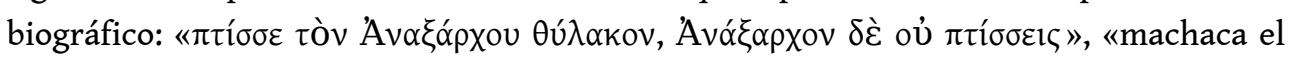
saco de Anaxarco, que a Anaxarco no lo dañas» (DL IX 59):

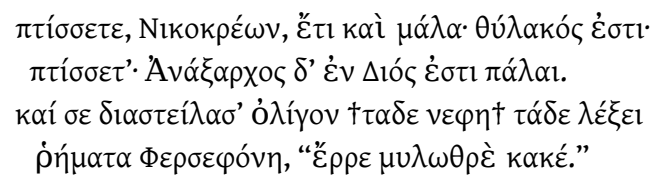


Muele, oh Nicocreonte, aún más: que es tan sólo un saco;

muele: Anaxarco ya mucho ha que está junto a Zeus.

Perséfone pronto vendrá [...] a cardarte,

diciendo: «Mal haya de ti, vil y ruin moledor.» [Trad. L.-A. Bredlow, ligeramente

modificada]

El mismo tema se encuentra en el epigrama en honor de Zenón de Elea, otra gloriosa víctima de la tortura de los tiranos, esta vez por obra de Nearco (o Diomedonte, según otras fuentes); en esta ocasión no se menciona la apoteosis celestial junto a Zeus, pero se retoma el tema del cuerpo del filósofo vacío de sí mismo (DL IX 28):

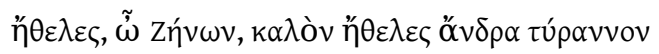

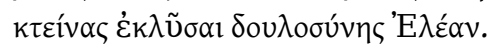

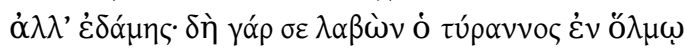

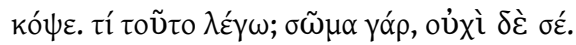

Quisiste, Zenón, y fue noble el intento, al señor y tirano

dándole muerte, librar de servidumbre a Elea.

Mas sucumbiste: al prenderte el tirano, moler en mortero

te hizo. ¿Qué digo yo? Sólo a tu cuerpo, no a ti. [Trad. L.-A. Bredlow]

El culto heroico reservado para los tiranicidas está bien establecido en la antigua Grecia, ya desde Harmodio y Aristogitón, quienes lo recibieron en Atenas (Demóstenes XIX 280; Pólux VIII 91 ${ }^{40}$. Pero lo cierto es que la misma fórmula se encuentra también en el epigrama de algún filósofo que no murió por la violencia de un tirano, sino de una muerte plácida y tranquila, que la tradición biográfica considera una buena muerte ${ }^{41}$. Es el caso de Polemón (DL IV 20):

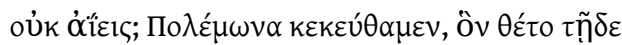

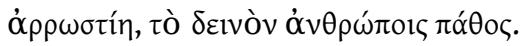

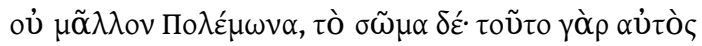

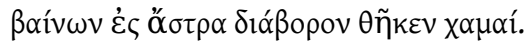

¿No lo ves? Que aquí Polemón reposando está, que lo trajo

el morbo, tan tremendo mal para los hombres.

No es Polemón: es su cuerpo que, cuando él mismo a los astros

se puso en marcha, aquí en tierra lo dejó. [Trad. L.-A. Bredlow]

Estos epigramas ofrecen, pues, una perspectiva particularmente interesante desde el punto de vista de la evolución de los tópicos biográficos, ya que preludian, cuanto menos en la forma, el esquema literario de la apoteosis cristiana posterior, evidentemente también celestial, en que el mártir demuestra su firmeza en la tortura, introduce frases lapidarias en el momento de su muerte y su alma abandona el cuerpo para remontar al cielo, la casa de $\operatorname{Dios}^{42}$. De hecho, en la mayoría de las apoteosis comentadas hasta ahora, los límites entre la adoración heroica y la divina, en particular la posición que los dioses y los héroes tienen en el sistema religioso griego antiguo, vacilan manifiestamente: los filósofos son equiparados a los dioses, honrados como dioses, y, sobre todo, como hemos visto, el carácter ctónico que los estudiosos han atribuido a menudo a los héroes ${ }^{43}$ no aparece en absoluto, sino que se trata con cierta frecuencia de heroificaciones celestiales.

Luciano de Samósata hace una buena parodia de este proceso heroificador en su narración de la muerte del cínico Peregrino: a los estúpidos que le pedían el relato de su muerte en la pira les contó que en ese momento ocurrió un terremoto, e inmediatamente después un grifo surgió de las llamas, y, mientras volaba al cielo,

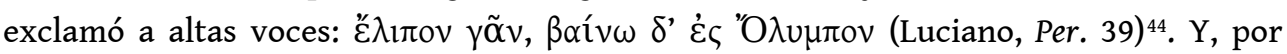
supuesto, la famosa apoteosis de Apolonio de Tiana retoma esta misma imagen: en el 
templo de Ártemis en Creta, las puertas se cerraron tras él y se escuchó un grito de

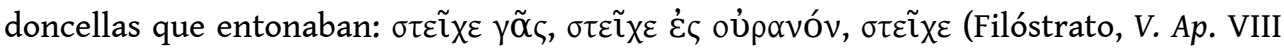
30). Como sucedía, según hemos visto, con algunos de los filósofos antiguos, el carácter divino le fue reconocido a Apolonio ya en vida (Filóstrato, V. Ap. III 50; IV 31; V 24; VII $11,21,31,38)$, y podemos indicar su antecedente más claro en la muerte de Empédocles: uno de sus discípulos también escuchó a medianoche una voz extraordinaria que llamó al filósofo, e inmediatamente después vio una luz celestial y un destello de antorchas; convencidos de la apoteosis del maestro, le ofrecieron sacrificios como si fuera un dios (DL VIII 68), y, más tarde, su amigo Pausanias erigió un monumento funerario y un espacio sagrado en su honor (DL VIII 71). Sin embargo, nunca hay, en las biografías laercianas, una escena como la de Apolonio de Tiana en que el filósofo se presente después de su muerte a los discípulos para confirmar su nuevo estatuto divino (Filóstrato, V. Ap. VIII 31).

\section{Las preferencias de Diógenes Laercio por las versiones menos heroizantes}

21 Para los filósofos de las vidas laercianas, ciertamente, la narración biográfica tiende a no aceptar semejantes prodigios, sino que más bien trata de negarlos: esta es, precisamente, una diferencia importante entre la biografía, y, por lo tanto, la imagen, de los filósofos antes y después del siglo IV d.C., cuando la difusión de los llamados $\theta \varepsilon i ̃ o 1$ ö $v \delta \rho \varepsilon \varsigma$ se vuelve más generalizada. Diógenes Laercio prefiere, por ejemplo, para la muerte de Empédocles, la versión de Hipóboto (fr. 16 Gigante), según la cual el filósofo quería a cualquier precio ser considerado divino, y por eso se arrojó al cráter del Etna, pero el volcán escupió una de sus famosas sandalias de bronce, y así se descubrió el engaño; o, para refutar su apoteosis celestial, cuenta Laercio que fue el mismo filósofo quien dio instrucciones a uno de sus sirvientes para que afirmara que lo habían visto ascender al cielo en medio de clamores y resplandor (DL VIII 69). Al igual que el Peregrino de Luciano, comentado anteriormente, Empédocles habría tratado de convertirse en divino siguiendo la vía de Heracles, mediante el fuego ${ }^{45}$. Timeo (FGrHist $566 \mathrm{~F}$ 6), sin embargo, declara que Empédocles había muerto en el exilio, en el Peloponeso, donde en sus días aún se podía visitar su tumba (DL VIII 71), y reprocha duramente a Heraclides Póntico que hubiera defendido, en cambio, la versión divinizante (fr. 84 Wehrli = fr. 4 Schütrumpf): no cabe duda de cuál es la versión que prefería Laercio.

Asimismo, que Pitágoras fuera venerado como un dios ya mientras vivía es una evidencia que sólo se manifiesta con absoluta claridad en las fuentes tardías: según Jámblico, sus discípulos contaban a Pitágoras entre los seres divinos, como si fuera un demon benigno para los hombres, y afirmaron que era la forma humana de Apolo Pitio, o Hiperbóreo, o Peán, o bien uno de los démones de la Luna, o, aún, uno de los Olímpicos que habría venido a la tierra para corregir la vida de los mortales y otorgarles la felicidad salvífica de la filosofía (Vit. Pyth. XXX) ${ }^{46}$. Aristóteles afirma que Pitágoras era venerado en Italia aún en su época (Rhet. 1398b), y parece que la casa donde se reunían sus discípulos en Metaponte se convirtió en un templo en honor a Deméter, mientras que el jardín de la entrada quedó consagrado a las Musas (Porfirio, V. P. IV; Jámblico, Vit. Pyth. CLXX); bien pudiera ser que Pitágoras recibiera culto en este espacio sagrado después de su muerte ${ }^{47}$. El lugar fue visitado también por Cicerón (Fin. 
$\mathrm{V} 2,4)^{48}$. Sin embargo, nada de esto es reportado por Laercio ${ }^{49}$, que se remite, al contrario, a la autoridad de Hermipo, quien planteó un escepticismo radical a propósito de la famosa catábasis de Pitágoras al Hades (DL VIII 21) ${ }^{50}$, exponiendo su engaño: el filósofo habría construido en secreto una habitación subterránea a su llegada a Italia, como Zalmoxis en el relato de Heródoto (IV 95), y su madre lo habría mantenido conectado con el exterior por medio de unas tablillas escritas que le iba pasando; al cabo de un tiempo, Pitágoras se presentó a sus conciudadanos, quienes creyeron que había vuelto del Hades y le tributaron grandes honores (DL VIII 41) ${ }^{51}$. El mismo Hermipo también desenmascaró la famosa resurrección de una chica obrada por Empédocles, explicando que en realidad todavía estaba viva cuando el filósofo la encontró (DL VIII 69 = fr. 27 Wehrli $=$ FGrHistCont 1026 F 62). Que Laercio prefería las versiones menos divinizantes se nota, como de costumbre, en las epigramas, que en este caso son particularmente malévolos; para Pitágoras (DL VIII 44):

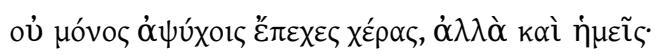

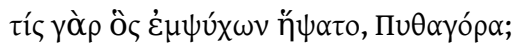

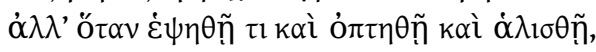

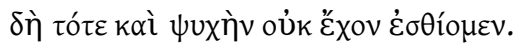

No sólo tú no comías, Pitágoras, seres con alma:

¿O es que quien sea jamás seres con alma comió?

Pues lo que está bien cocido y asado y salado a gusto,

eso sin alma ya sírvese para comer.

y para Empédocles (DL VIII 75):

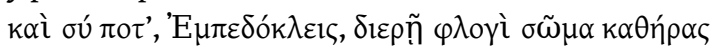

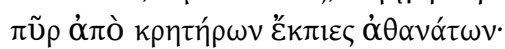

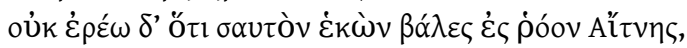

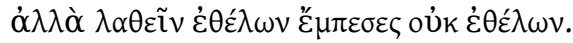

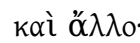

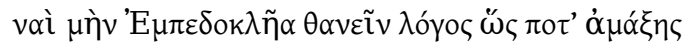

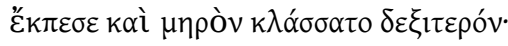

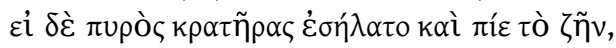

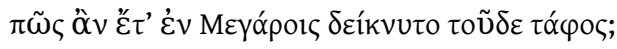

En depurándote, Empédocles, a llama viva el cuerpo,

tú del bocal del volcán fuego bebiste inmortal.

No digo yo que de grado al ardor te arrojaste del Etna,

no: por quererte ocultar caíste en él sin querer.

Y otro:

Cierto que es fama que ha muerto Empédocles cuando al caerse

desde el carro se fue el fémur derecho a romper.

Pues si al cráter de fuego saltando apuraba su vida,

¿Cómo en Mégara aún hoy su sepulcro se ve? [Trad. L.-A. Bredlow]

También son muy interesantes los casos, en las biografías laercianas, en que se descubre el engaño y los filósofos permanecen de este modo refutados para siempre. Esto le sucede a Heraclides Póntico, el ejemplo más claro: según Demetrio de Magnesia (F 18 Mejer) e Hipóboto (fr. 7 Gigante), crió una serpiente con la intención de hacerla aparecer en su lecho de muerte, para que la multitud congregada entendiera que había sido heroizado ${ }^{52}$, seguramente influenciado por el relato plutarqueo en que Ptolomeo Filopátor veneraba el cadáver de Cleómenes después de haberlo crucificado, porque una serpiente apareció cerca de su cabeza e impidió que los buitres se la comieran, y

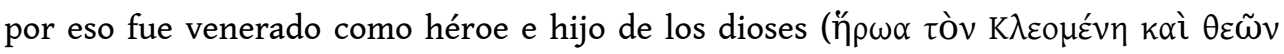
$\pi \alpha \tilde{\delta} \delta \alpha \pi \rho \circ \alpha \gamma о \rho \varepsilon v ́ o v \tau \varepsilon \zeta)$, habida cuenta de que, como recuerda Plutarco (Vida de

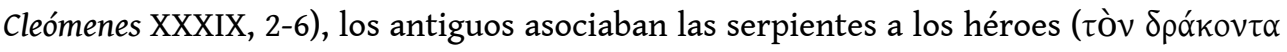




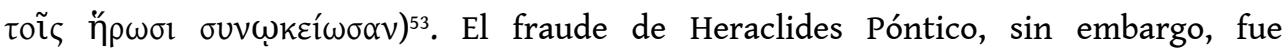
descubierto a tiempo y el filósofo quedó completamente denigrado (DL V 89-90), como se manifiesta claramente, una vez más, en el epigrama que le dedica Laercio (DL V 90):

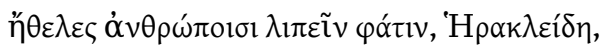

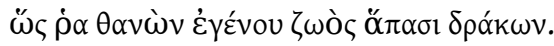

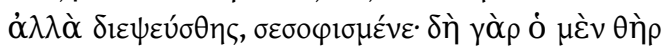

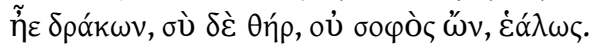

A todos los hombres quisiste dejar, Heraclides, la fama

que una vez muerto tornaste, hecho serpiente, a vivir.

Pero tú te pasaste de listo, pilluelo: pues sí, que la bestia

sí fue serpiente; al revés, el animal fuiste tú. [Trad. L.-A. Bredlow]

La versión de Hermipo (fr. 42 Wehrli = FGrHistCont 1026 F 71), que se reencuentra también en los Acad. Index Herc. col. IX-X, es todavía más novelesca: Heraclides llegó al extremo de sobornar a la Pitia délfica para que proclamase que sus conciudadanos debían ofrecer al filósofo una corona de oro en vida y, después de su muerte, instituir un culto heroico en su honor; pero, mientras Heraclides era coronado en el teatro, murió de una apoplejía fulminante, los mensajeros del oráculo fueron apedreados, y la

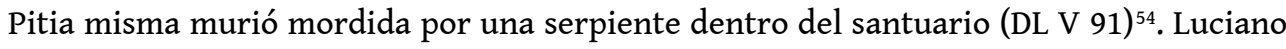
de Samósata será aún más sarcástico al contar la muerte del falsario Alejandro de Abonutico, quien también tenía una serpiente escondida bajo su túnica y la mostraba para atraer la admiración de las gentes (Alex. 26): Luciano ni siquiera permite entrever un castigo divino en su muerte fulminante, al estilo de la de Heraclides, sino que su final debe atribuirse, según él, tan sólo a la pura casualidad (Alex. 60).

\section{Algunas conclusiones: Diógenes Laercio y el culto a los filósofos}

Es, sea como sea, una evidencia que los filósofos antiguos fueron considerados, en la tradición biográfica, personajes susceptibles de recibir la misma heroización cultual que otras figuras históricas, particularmente legisladores, atletas y ciudadanos caídos por la patria, pero, sobre todo, poetas, con quienes muestran una mayor cercanía, en el sentido de que ambos fueron heroificados en gran medida por su бopía y por sus obras, y su culto comienza en torno a una forma de comunidad ${ }^{55}$. Este proceso de establecimiento primigenio de cultos para los principales filósofos coincide, por supuesto, con procesos similares para otros operadores culturales y personalidades ilustres de todo tipo que comienza en el siglo IV a.C. y no deja de acrecentarse en la era helenística, cuando el culto a los soberanos contribuye notablemente a que el desarrollo de la heroización de personajes históricos sea más frecuente y estereotipada ${ }^{56}$. Se trata, sin duda, de un memorializing impulse $e^{57}$, que pretende honrar a los grandes personajes del pasado en cada ciudad y mantener viva su herencia cultural, pero, al mismo tiempo, busca ejercer un control sobre esta heredad y dirigirla. En este mismo sentido, no es extraño que la mayoría de los epigramas en honor de los grandes autores del pasado pertenezcan a este período, con las referencias biográficas que inevitablemente conllevan, así como los detalles de sus formas de morir, y el significado que estas muertes les otorgan según los parámetros significativos de la tradición ${ }^{58}$ : el restablecimiento de los cultos a los grandes poetas del pasado ${ }^{59}$, los $\pi i ́ v \alpha k \varepsilon \zeta$ biobibliográficos de Calímaco y de Hermipo, e inluso los epigramas literarios 
pertenecen a este mismo interés por mantener la memoria colectiva de las grandes figuras intelectuales del pasado.

Asimismo, a pesar de las diferencias, poetas y filósofos recibieron cultos post mortem bastante similares. Como en el caso de los poetas, la tumba del filósofo glorifica a la ciudad que la posee, su funeral es generalmente público y suntuoso, al modo que corresponde a un benefactor de la comunidad, se erigen estatuas en su honor, se le escriben epigramas que subrayan su naturaleza divina y a menudo son objeto de culto heroico en términos similares a los de los poetas ${ }^{60}$. De hecho, los poetas contemporáneos también deseaban este culto post mortem que promovieron para los poetas del pasado: Posidipo, por ejemplo, lo expresa muy claramente cuando le pide a Apolo un oráculo que prescriba para él los mismos honores que había prescrito para Arquíloco (Suppl. Hell. 705, 11-17).

Ahora bien, a pesar de las referencias, notables, aunque no muy numerosas, a estas formas de honores fúnebres colectivos y a los cultos heroicos tributados a los filósofos, es reseñable que, muy significativamente, ni Pitágoras ni Epicuro, cuya divinización es clara en otras fuentes y se explora en diversos estudios modernos, sean heroificados explícitamente en Diógenes Laercio. Aún más significativo: Laercio generalmente prefiere tradiciones biográficas negativas que ven como falsarios a filósofos que pretenden dar pruebas, en el momento de su muerte, de su apoteosis fingida. Resulta

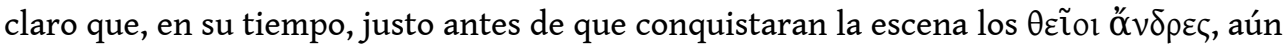
no se había desarrollado ese gusto por la taumaturgia, la divinización y los relatos repletos de prodigios que pronto atraería completamente al público de biografías ${ }^{61}$. Baste comparar, en este punto como en muchos otros, las biografías laercianas con las de Eunapio de Sardes ${ }^{62}$ : las divergencias de enfoque entre ambos autores definen extraordinariamente cuán distintos eran su contexto cultural y los horizontes de expectativas de su público. Diógenes Laercio se incardina ideológicamente entre los autores que se muestran escépticos con los episodios taumatúrgicos de las vidas de los filósofos, en la línea de Hermipo e Hipóboto, con un tono cercano incluso al de Luciano de Samósata, en la denuncia de los charlatanes y falsarios, y que comparte asimismo con otros autores anticuarios, como Aulo Gelio o Ateneo.

Queda, sin embargo, una paradoja por tratar de explicar: a pesar de sus reticencias a la hora de relatar los indicios de heroizaciones y cultos heroicos en el cuerpo de la narración biográfica, son numerosos los epigramas en los que el mismo Laercio refiere el carácter heroico de diversos filósofos, tal como hemos visto, particularmente en forma de apoteosis celestial. Parecería que Laercio siguiera preferentemente las fuentes helenísticas en el cuerpo de la narración biográfica en prosa, pero dejara, en cambio, para los epigramas, de su propia cosecha y gusto, los nuevos aires, por así decir, de la biografía de filósofos taumaturgos y divinos que empezaba a imponerse en sus días -no olvidemos que la Vida de Apolonio de Tiana de Filóstrato es prácticamente contemporánea de la obra laerciana- y que estaba destinada a ocupar bien pronto Jámblico y Porfirio son tan sólo unos años posteriores- todo el panorama de los relatos biográficos del momento, hasta alcanzar e influenciar notablemente la naciente hagiografía. Teniendo en cuenta que los epigramas suelen ser el espacio donde Laercio expresa su personal enjuiciamiento final de la vida y la muerte de los filósofos que han sido objeto de las biografías ${ }^{63}$, no sería descabellado pensar, quizás, que es aquí por donde se cuelan estos nuevos aires de su época, mientras que el resto de la obra se atiene todavía, como en todo lo demás, a la tradición tomada de sus fuentes, que 
recogen únicamente, como es bien sabido, vidas y doctrinas de filósofos anteriores al siglo I dC.

\section{BIBLIOGRAFÍA}

Beretta, Citti, IAnnucci 2014: M. Beretta, F. Citti, A. Iannucci (eds.), Il culto di Epicuro. Testi, iconografia e paesaggio, Firenze 2014.

BING 1988a: P. Bing, The Well-Read Muse: Present and Past in Callimachus and the Hellenistic Poets, Hypomnemata 90, Göttingen 1988.

BING 1988b: P. Bing, «Theocritus' Epigrams on the Statues of Ancient Poets», Antike und Abendland 34 (1988), 117-123.

BING 1993: P. Bing, «The Bios-Tradition and Poets' Lives in Hellenistic Poetry», en R. M. Rosen, J. Farrell (eds.), Nomodeiktes. Greek Studies in Honor of Martin Ostwald, Ann Arbor 1993, 619-631.

BOYANCÉ 1972: P. Boyancé, Le culte des Muses chez les philosophes grecs, Paris 1972.

BREDLOW 2010: L.-A. Bredlow, Diógenes Laercio. Vidas y opiniones de los filósofos ilustres, Zamora 2010.

BRELICH 1958 [2010]: A. Brelich, Gli eroi greci. Un problema storico-religioso, Roma 1958 [reimpr. 2010].

BURKERT 1962 [1972]: W. Burkert, Weisheit und Wissenschaft: Studien zu Pythagoras, Philolaos und Platon, Nüremberg 1962 [citamos por la traducción inglesa: Lore and Science in Ancient Pythagoreanism, Cambridge 1972].

BURKERT 1985: W. Burkert, Greek Religion, Cambridge, MA 1985.

CLARK 1973: M. L. Clark, «The Garden of Epicurus», Phoenix 27 (1973), 386-387.

CLAY 1972: D. Clay, «Socrates’ Mulishness and Heroism», Phronesis 17 (1972), 53-60.

CLAY 1986: D. Clay, «The cults of Epicurus», Cronache Ercolanesi 16 (1986), 12-28 [= Paradosis and Survival: Three chapters in the History of Epicurean Philosophy, Ann Arbor 1998, 75-102, versión revisada].

CLAY 1991: D. Clay, «Lucian of Samosata: Four Philosophical Lives (Nigrinus, Demonax, Peregrinus, Alexander Pseudomantis)», Aufstieg und Niedergang des Römischen Welt, Band II. 36. 5, New York Berlin 1991, 3406-3450.

CLAY 2004: D. Clay, Archilochos Heros. The Cults of Poets in the Greek Polis, Cambridge Mass. 2004.

CRÖNERT 1905 [1965]: W. Crönert, Kolotes und Menedemos. Texte und Untersuchungen zur Philosopheund Literaturgeschichte, Leipzig 1905 [reimpr. Amsterdam 1965].

CURD 2007: P. Curd, Anaxagoras of Clazomenae. Fragments and Testimonia, Toronto 2007.

DARAKI 1986: M. Daraki, «La sagesse des Cyniques grecs», en C. Mossé (ed.), La Grèce ancienne, Paris 1986, 92-108.

DiMAKIS 1987: D. P. Dimakis, «Note al testamento di Epicuro», Studi Biscardi VI (1987), 471-492. 
DoRANDI 1991: T. Dorandi, «Precisazioni sul testamento di Epicuro», Labeo 38 (1991), 55-62.

DoRANDI 2013: T. Dorandi (ed.), Diogenes Laertius, Lives of Eminent Philosophers, Cambridge - New York 2013.

EDWARDS 1989: M. J. Edwards, «Satire and Verisimilitude: Christianity in Lucian's "Peregrinus"», Historia: Zeistschrift für Alte Geschichte 38 (1989), 89-98.

ЕКRотн 2002: G. Ekroth, The Sacrificial Rituals of Greek Hero-Cults in the Archaic to the Early Hellenistic periods (Kernos suppl. 12), Liège 2002.

ERLER 2002: M. Erler, «Epicurs as deus mortalis: Homoiosis theoi and Epicurean Self-Cultivation», en D. Frede, A. Laks (eds.), Traditions of Theology. Studies in Hellenistic Theology, its Background and Aftermath, Leiden 2002, 159-181.

ERLER 2014: M. Erler, «La sacralizzazione di Socrate e di Epicuro», en M. Beretta, F. Citti, A. Iannucci (eds.), Il culto di Epicuro. Testi, iconografia e paesaggio, Firenze 2014, 1-13.

FAIRWEATHER 1974: J. Fairweather, «Fiction in the Biographies of Ancient Writers», Ancient Society 5 (1974), 231-275.

FAIRWEATHER 1983: J. Fairweather, «Traditional Narratives, Influence and Truth in the Lives of the Greek Poets», Papers of the Liverpool Latin Seminar 4 (1983), 315-369.

FARNELL 1921 [1970]: L. R. Farnell, Greek hero cults and ideas of immortality, Oxford 1921 [reimpr. 1970].

FIELDS 2013: D. Fields, «The reflections of satire: Lucian and Peregrinus», Transactions of the American Philological Association 143 (2013), 213-245.

GRAU, NARRO 2013: S. Grau, Á. Narro «Vidas de filósofos y hechos apócrifos de los apóstoles: algunos contactos y elementos comunes», Estudios Clásicos 143 (2013), 65-92.

GRAU 2010a: S. Grau, «Tipificación en la biografía griega antigua de filósofos: la construcción de una imagen preconcebida», Espíritu 140 (2010), 435-492.

GRAU 2010b: S. Grau, «How to kill a philosopher. The narrating of ancient greek philosophers' deaths in relation to their way of living», Ancient Philosophy 30 (2010), 347-381.

GRAU 2013: S. Grau, «Diogenes Laertius between tradition and innovation: philosophers and $\theta \varepsilon \tilde{\text { Iol }}$ ő $v \delta \rho \varepsilon \varsigma »$, en R. García-Gasco, S. González Sánchez, D. Hernández de la Fuente (eds.), The Theodosian Age (A.D. 379-455): Power, Place, Belief and Learning at the End of the Western Empire, Oxford 2013, 183-189.

GRAU 2015: S. Grau, «Las burlas del ascetismo en la biografía de los filósofos griegos antiguos: ¿un reaprovechamiento de materiales cómicos?», en J. De la Villa, P. Cañizares, E. Falque, J. F. González, J. Siles (eds.), Ianua Classicorum. Temas y formas del Mundo Clásico, Madrid 2015, vol. II, 171-178.

GRAU 2018: S. Grau, «Miracles de filòsofs entre Diògenes Laerci i Eunapi de Sardes: formes i funcions», en M. Movellán Luis, J. J. Pomer Monferrer (eds.), Mite i miracle a les literatures antigues $i$ medievals, Reus 2018, 43-60.

HAAKE 2015: M. Haake, «Philosophical Schools in Athenian Society from the Fourth to the First Century BC: An Overview», en V. Gabrielsen, C. A. Thomsen, Private Associations and the Public Sphere. Proceedings of a Symposium held at the Royal Danish Academy of Sciences and Letters, 9-11 September 2010, Copenhagen 2015, 57-91. 
KIMMEL-CLAUZET 2013: F. Kimmel-Clauzet, Morts, tombeaux et cultes des poètes grecs. Étude de la survie des grands poètes des époques archaïque et classique en Grèce ancienne, Bordeaux 2013.

KIVILO 2010: M. Kivilo, Early Greek Poets' Lives: the Shaping of the Tradition, Leiden - Boston 2010.

Koch PIETTRE 1999: R. Koch Piettre, «Épicure, dieu et image de dieu : une autarcie extatique», Revue de l'histoire des religions 216 (1999), 5-30.

Koch PietTRE 2005: R. Koch Piettre, Comment peut-on être dieu ? La secte d'Épicure, Paris 2005.

KÜSTER 1913: E. Küster, Die Schlange in der griechischen Kunst und Religion, Giessen 1913.

LEFKOWITZ 1979: M. R. Lefkowitz, «The Euripides Vita», Greek, Roman \& Byzantine Studies 20 (1979), 187-210.

LEFKOWITZ 1981: M. R. Lefkowitz, The Lives of the Greek Poets, Baltimore 1981.

LEFKowitZ 2009: M. R. Lefkowitz, «Biographical Mythology», en U. Dill, Ch. Walde (eds.), Antike Mythen: Medien, Transformationen, und Konstruktionen (Studien in Honorem Fritz Graf) Berlin 2009, 516-531.

LONGO AURICCHIO 2014: F. Longo Auricchio, «Il culto di Epicuro: testi e studi. Qualche aggiornamento», en M. Beretta, F. Citti, A. Iannucci (eds.), Il culto di Epicuro. Testi, iconografia e paesaggio, Firenze 2014, 39-64.

LóPEz CRUCES 2004: J. L. López Cruces, «Sófocles, Diógenes y Cércidas», en A. Pérez Jiménez, C. Alcalde, R. Caballero (eds.), Sófocles el hombre, Sófocles el poeta. Congreso internacional con motivo del XXV centenario del nacimiento de Sófocles (497/6 aC. - 2003/4), Málaga, 29-31 de mayo de 2003, Málaga 2004, 245-257.

LORAUX 1985: N. Loraux, «Socrate, Platon, Héraklès: Sur un paradigme hérö̈que du philosophe», en J. Brunschwig, Cl. Imbert, A. Roger (edd.), Histoire et structure, à la memoire de V. Goldschmidt, Paris 1985, 93-105.

MojsIK 2017: T. Mojsik, «Dicearchus (fr. 41 Mirhady) on Pythagoras' Death», Eos CIV (2017), 47-69. Muccioli 2014a : F. Muccioli, «Le ambizioni del filosofo. Le tradizioni sulla morte di Eraclide Pontico», Electrum 21 (2014), 9-19.

Muccioli 2014b : F. Muccioli, «Cultes héroïques et cultes divins aux IV et III $^{\mathrm{e}}$ siècles av. J.-C. Tradition, innovation et reflets littéraires», Mythos 8 (2014), 13-33.

Muccioli 2015: F. Muccioli, «Diventare un dio a Selinunte? Empedocle e la bonifica/purificazione della città», en A. Iannucci, F. Muccioli, M. Zaccarini (eds.), La città inquieta. Politica, religione e controllo sociale a Selinunte tra lex sacra e defixiones, Milano-Udine 2015, 261-284.

NAGY 2013: G. Nagy, The Ancient Greek Hero in 24 Hours, Cambridge, Mass.-London 2013.

NIETZSCHE 1868: F. Nietzsche, «De Laertii Diogenis fontibus», Rheinisches Museum 23 (1868), 632-653.

Notopoulos 1942: J. A. Notopoulos, «Plato’s Epitaph», American Journal of Philology 63 (1942),

272-293.

OGDEN 2013: D. Ogden, Dragons, Serpents, and Slayers in the Classical and Early Christian Worlds, Oxford 2013.

RIGINOS 1976: A. S. Riginos, Platonica. The anecdotes concerning the life and writings of Plato, Leiden 1976. 
SANTAMARÍA ÁlVAREZ 2016 : M. A. Santamaría Álvarez, «La catábasis de Pitágoras», Emerita LXXXIV (2016), 31-50.

TALBERT 1978: C. H. Talbert, «Biographies of Philosophers and Rulers as Instrumental of Religious Propaganda in Mediterranean Antiquity», en Aufstieg und Niedergang des Römischen Welt, Band 16, 2, New York - Berlin 1978, 1619-1651.

TARÁN 1984: L. Tarán, «Plato's alleged epitaph», Greek, Roman \& Byzantine Studies 25 (1984), 63-82.

Temmerman, Demoen 2016: K. de Temmerman, K. Demoen (eds.), Writing Biography in Greece and Rome. Narrative Technique and Fictionalization, Cambridge 2016.

USENER 1887: H. Usener, Epicurea, Leipzig 1887.

VALlET 1974: G. Vallet, «Le Stenopos des Muses à Métaponte», Mélanges P. Boyancé (1974), 749-759.

VOUTIRAS 2000: E. Voutiras, «Le cadavre et le serpent, ou l'hérö̈sation manquée de Cléomène de Sparte», Kernos suppl. 10 (2000), 377-394.

WILAMOWITZ 1881: U. Von Wilamowitz-Möllendorff, Antigonos von Karystos, «Philologishe Untersuchungen» IV, Berlin 1881.

VEILLARD 2009: C. Veillard, «Les Vies des philosophes de Diogène Laërce: une reflexión sur l'histoire de la philosophie», Dissertatio 30 (2009), 73-92.

\section{NOTAS}

1. Filodemo pretende argumentar que sólo Epicuro y los epicúreos permanecieron exentos de los ataques de la Comedia, pero en realidad tampoco él se sustrae a las críticas: al igual que los otros filósofos, Epicuro y sus discípulos fueron parodiados en la Comedia Media como maestros de los

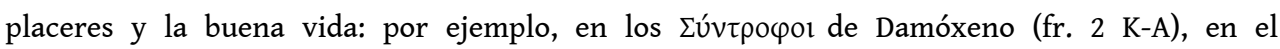

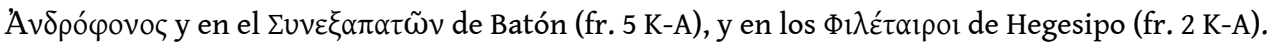

2. Sobre esta caracterización general de los filósofos, véase GRAU 2015. Conviene dejar claras de buen principio las bases metodológicas que regirán el presente análisis de las fuentes antiguas. Como es habitual en los estudios de los últimos decenios en el ámbito de la biografía antigua, no intentaremos en ningún caso dar cuenta de la historicidad real de las anécdotas o de las imágenes de los personajes que en ellas se construyen, ni de los contextos de producción de los textos que las incluyen, puesto que se trata de estudiar la tipificación de un elemento narrativo común a las biografías de los filósofos y su evolución a lo largo de la Antigüedad. En este sentido, hablaremos constantemente de 'la tradición biográfica' o 'la biografía' para referirnos al relato que hacen de las vidas de los filósofos las diversas fuentes biográficas antiguas, no a los hechos históricos propiamente dichos que son referidos sólo cuando conviene a la argumentación. Sirvan de referencia metodológica para este procedimiento las obras de FAIRWEATHER 1974 y 1983; LEFKOWITZ 1981 y 2009; Kivilo 2010; Grau 2010a; Temmerman, Demoen 2016. Para todas las citas del texto griego de Diógenes Laercio seguimos, por supuesto, la edición de DoRANDI 2013.

3. Véase la lista de términos ‘técnicos' recopilados por ЕКRОТН 2002.

4. Véase LefKowitz 1979, 203; KimMEL-CLAUZET 2013, 35-119.

5. Véase especialmente BURKERT 1985, 105-107.

6. Para la tipología de las muertes de los filósofos antiguos y su significación, véase GRAU $2010 b$.

7. Además de las evidencias recopiladas por FARNELL 1921, véanse CLAY 2004, 127-153, y KIMMELCLAUZET 2013, para los datos sobre cultos a poetas. 
8. Véase Riginos 1976, 30-32. También la Vita anonyma se refiere a este carácter apolíneo de Platón en diversos pasajes: Vita anonyma 23-24, 46-48, 157 Westernik.

9. Según Pausanias IX 23, 2-3, Filóstrato, Imagines II 12, y Eustacio, Vida de Píndaro XXVII 12-14 Kambylis.

10. Lo afirmaba con contundecia Riginos 1976, 31: «The insistence that the philosopher, not the poet, is the true servant of Apollo is an expression of Plato's opposition to the poets and the poetry».

11. FARNELL 1921 [1970], 362.

12. Véase CLAY 1991, 3414-3420. De hecho, es verosímil que se haya producido aquí una confusión entre Menedemo y Menipo, como señalaba CRÖNERT 1905 [1965], 1-4.

13. Véase CURD 2007, 136.

14. FARNell 1921 [1970], 361. De hecho, Justino (III 4) da un paso más al afirmar que sus restos fueron diseminados por el ágora y la ciudad decretó honores divinos para él. Una tradición diferente es la que recoge Eliano (VH VIII 16): Solón habría sido objeto de un culto público alrededor de su sepulcro, una tumba rodeada por un muro, cerca de las puertas de la ciudad de Atenas. Sin embargo, no hay ninguna otra evidencia de esta tradición.

15. O generales, como Brásidas, muerto en 422 a.C., que fue honrado con un culto como segundo fundador de la ciudad en el ágora de Atenas (Tucídides V 11), o Arato de Sición, muerto en 231 a.C. (Plutarco, Arato LIII 3). El modelo cultual es, por supuesto, el héroe fundador, como el conocido Bato de Cirene, descrito por Píndaro (Pítica V, 93-98). Lo confirma claramente un escolio

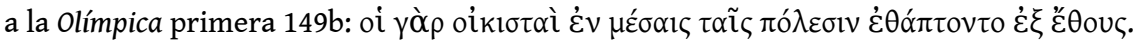

16. FARNELL 1921 [1970], 361.

17. Para las evidencias, véanse CIG 1256; Heródoto I 65; Estrabón 366; FHG 3, 390; y también FARNELL 1921 [1970], 361.

18. O bien un Bianteo, según las IPriene 11.245, 113.88 y 117.34 .

19. Véase FARNELL 1921 [1970], 326-327: «the cult is a reward for patriotism».

20. Véase BoYANCÉ 1972, 316: «Il semble qu'on doive déduire qu'Aristote n'était point le parèdre des Muses et n'était pas à proprement parler héroïsé, puisque son portrait paraît simplement qualifié d'ó $v \alpha \theta \tilde{\eta} \mu \alpha »$.

21. BOYANCÉ 1972, 273.

22. Los ejemplos más evidentes son, de hecho, dos atletas: Teágenes de Tasos (Pausanias VI 11, 8) y, sobre todo, Cleomedes de Astipalea (Pausanias VI 9, 7), que recibe una respuesta oracular muy similar a esta de Platón.

23. Sobre estos epitafios, cuya fuente Laercio no menciona, véanse NOTOPOULOS 1942 y TARÁN 1984.

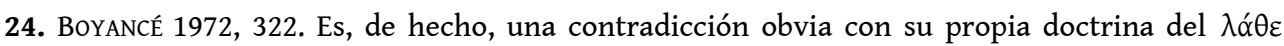
$\beta \iota \omega ́ \sigma \alpha \varsigma$, como Plutarco denuncia en varias ocasiones (1129a; 1089c).

25. Véase, asimismo, Lucrecio III 322: dignam dis degere uitam.

26. Conviene señalar que Filóstrato -y también otros autores de época imperial- define como

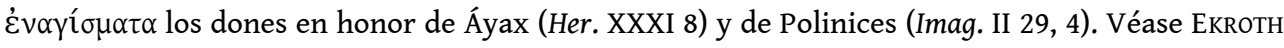
2002, 104-128.

27. Para un estudio del testamento de Epicuro, véanse DIMAKIS 1987 y DoRANDI 1991.

28. Epicuri uoltus per cubicula gestant ac circumferunt secum. Natali eius sacrificant, feriasque omni mense custodiunt uicessima luna quas icadas uocant, precisamente aquellos que se ne uiuentes quidem nosci uolunt. Véase, también, Eliano, fr. 39, que da los mismos detalles.

29. BOYANCÉ 1972, 324.

30. BOYANCÉ 1972, 327.

31. Véanse, particularmente, Koch PietTre 1999, Koch Piettre 2005, ERLer 2002, Longo Auricchio 2014, ERLER 2014 y BERETTA, CITTI, IANNUCCI 2014.

32. CLAY 1986, 11, nota 2. 
33. Véase su artículo «Heros», en el Röschers Lexikon, col. 2534 ss.

34. Clay 1986, 27.

35. Así lo creen CLAY 1986, 26-27, y CLARK 1973, 386.

36. WiLAMOWITZ 1881, 321; CRÖNERT 1905 [1965], 140. En contra, U SENER 1887, XXII, y NiETZSCHE 1868, 641, quien puso de manifiesto el sarcasmo contra Epicuro presente en el epigrama que le dedica (DL X 116) como una prueba irrefutable de que Laercio no podía ser epicúreo.

37. Véase DARAKI 1986, particularmente 99-100, y LÓPEZ CRUCES 2004.

38. Véase la sugerente exposición de esta caracterización heroica de Sócrates que hace NAGY 2013, 605-653.

39. CLAY 1972 desarrolla la idea de que Sócrates se compara con una mula (Platón, Conu. 221e, y, sobre todo, Ap. 27e) porque afirma ser un semidiós, como Aquiles y Heracles, en tanto que se sitúa entre hombres y dioses, como las mulas están entre burros y caballos. Para el parangón con Heracles, véase LORAUX 1985.

40. Véase ЕкRотн 2002, 82-86.

41. Véase GRAU 2010, 374-375.

42. Véase GraU, NARRo 2013.

43. Véase la síntesis de BURKERT 1985, 199-203, y las conclusiones del detallado estudio de EKROTH 2002, 310-341, para quien es evidente que la tradicional distinción entre ctónico y celeste aplicada a los héroes y los dioses no tinen ningún sentido desde el punto de vista ritual.

44. Entre la abundante bibliografía sobre este punto, cabe destacar particularmente los estudios de FIELDS 2013 y EDWARDS 1989.

45. Véase BRELICH 1958 [2010], 194. Para un estudio reciente sobre la divinización de Empédocles, véase Muccioli 2015.

46. Véase, también, Jámblico, Vit. Pyth. 53, 143, 150, 225.

47. Esta era la opinión de BOYANCÉ 1972, 234-235. Diversamente lo interpretaba VALLET 1974, quien

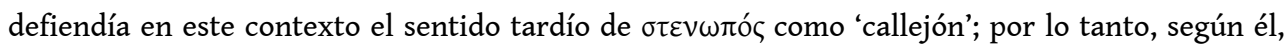

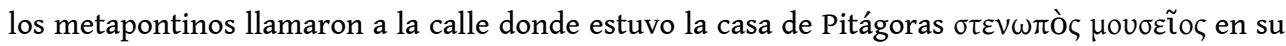
honor.

48. Scis enim me quodam tempore Metapontum uenisse tecum neque ad hospitem ante deuertisse quam Pythagorae ipsum illum locum ubi uitam ediderat, sedemque uiderim.

49. Ni tampoco por sus fuentes, por supuesto: véase MOJSIK 2017.

50. Véase el comentario de J. Bollansée al FGrHistCont 1026 F 25 de Hermipo.

51. En realidad, tal como demostró BURKERT 1962 [1972], 155-161, a pesar de su evidente tono satírico, el relato de Hermipo muestra signos de antigüedad: las instrucciones que Pitágoras recibe de su madre en realidad serían de la Madre, es decir, Deméter, con quien el filósofo está abiertamente vinculado para poder viajar al Hades. Hermipo ciertamente partió de una historia antigua y la convirtió en esta caricatura racionalista. Todavía hay ecos de ello en Luciano, Alex. IV 20. Veáse, sobre este tema, SANTAMARÍA ÁLVAREZ 2016.

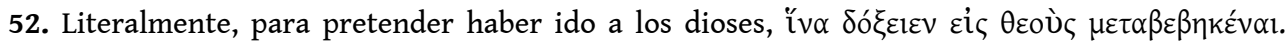
También en esta escena, evidentemente paródica, se encuentra la noción celestial, no ctónica, del héroe, como se ha comentado anteriormente. El mecanismo de heroización, sin embargo, por medio de la serpiente, sigue siendo claramente ctónico y tradicional: véanse FARNELL 1921 [1970], 366; BRELICH 1958 [2010], 220-222; BURKERT 1985, 195, 201. Para la serpiente como un animal tradicionalmente asociado a los héroes, el estudio clásico es el de KÜSTER 1913, pero véase, más recientemente, OGDEN 2013.

53. Sobre Cleómenes, véase VouTiRAs 2000.

54. Estoy sustancialmente de acuerdo con el análisis del pasaje que hace Muccioli 2014a.

55. Desde luego, no sería lícito retrotraer a épocas anteriores al siglo III d.C. los tipos de comunidades que describe TALBERT 1978, pero podemos afirmar que el culto a los filósofos no 
puede ser disociado de sus escuelas, como se hace patente en las instrucciones mismas de los testamentos de los grandes fundadores. Para el estatuto específico y el funcionamiento de estas instituciones, véase HAAKE 2015.

56. Véase, entre la abundante bibliografía, el resumen de Muccioli $2014 \mathrm{~b}$.

57. Por usar las palabras de BING 1993, que hace un interesante análisis del fenómeno.

58. Para los poetas, además de KIMMEL-CLAUZET 2013, 163-184, véanse los estudios de BING 1988a, 58-64 y BING 1988b. Para los epigramas en honor de los filósofos, véase GRAU 2013.

59. Son muestras claras de este proceso, por ejemplo, el Arquiloqueo de Paros, obra de Mnesíepes, el templo en honor de Homero en Alejandría (cf. Eliano, VH XIII 22), promovido por

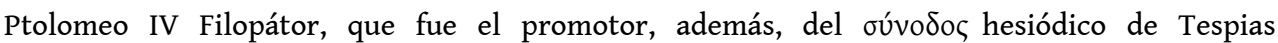
(Dittenberger, O.G.I. 1117 Sylloge, saec. II, prope Thespias) y de Esmirna (Estrabón XIV 1, 37; Cicerón, Arch. VIII).

60. Véase KimMEL-CLAUZET 2013, 123-271.

61. Véase GRAU 2013.

62. Véase GRAU 2018.

63. De hecho, es precisamente en los epigramas que Laercio añade al final de la mayoría de sus biografías donde es más fácil rastrear las simpatías y antipatías del autor hacia los diversos filósofos: sin duda, esta es la parte más personal de toda su obra, porque los poemas son fruto de su única creatividad y a menudo en ellos refleja cuál de las versiones expuestas en la parte en prosa es la que prefiere, o sencillamente expresa un juicio definitivo y categórico sobre cada filósofo (cf. VEILLARD 2009, pp. 78-79). Para un análisis sistemático de este procedimiento, remito a GRAU 2010b.

\section{RESÚMENES}

Es un dato hoy bien aceptado que, en algunos casos, existen evidencias de una verdadera heroización o divinización de los antiguos filósofos griegos después de su muerte, a través del establecimiento de un culto, o de un espacio sagrado, con un altar, que a veces también aparece testimoniado por documentos y excavaciones arqueológicas. Sin embargo, en las biografías de los filósofos de Diógenes Laercio, el epigrama es el medio habitual para sancionar la apoteosis de un filósofo. De hecho, rara vez aparece alguna referencia a este proceso religioso típicamente griego en el cuerpo de la narración, si no es, significativamente, para denunciar su falsedad. Me gustaría reflexionar, por lo tanto, no sólo sobre las evidencias del culto a los filósofos en la obra laerciana, sino también sobre la imagen que los griegos tenían del culto a sus filósofos en un período particularmente interesante, el que precede inmediatamente al desarrollo de la figura de los llamados pagan holy men, para observar sobre todo sus funciones narrativas.

It is now admitted without discussion that, in some cases, there is good evidence for a real heroification or deification of ancient Greek philosophers after their deaths, by establishing a cult, or a sacred space, with an altar, which is sometimes both witnessed by documents and discovered by archaeological excavations. In Diogenes Laertius' biographies of philosophers, however, the epigram is the usual mean to enshrine the apotheosis of a philosopher. In fact, references to this typically Greek religious process are seldom attested in the body of narrations, unless they are used precisely to denounce their falsehood. I will thus not be only concerned with 
the evidence for cult devoted to the philosophers in Diogenes Laertius, but rather with the view that the Greeks had about the cult to their philosophers in a particularly significant time, namely that immediately preceding the advent of the so-called pagan holy men, in order to observe mainly their narrative functions.

\section{ÍNDICE}

Keywords: Diogenes Laertius, Greek Biograhy, heroification, cults to ancient Greek philsophers, Greek Religion

Palabras claves: Diógenes Laercio, biografía griega, heroización, cultos a filósofos griegos antiguos, religión griega

\section{AUTOR}

\section{SERGI GRAU}

Universitat de Barcelona - Institut Català d'Arqueologia Clàssica

Facultat de Filologia i Comunicació

Gran Via de les Corts Catalanes, 585

08007 Barcelona

s.grau(at)ub.edu 